\title{
Using Electronic Collaborative Media according Organizational Culture
}

\author{
Mohammad Atwah Al-Ma'aitah \\ Al-Balqa Applied University
}

\begin{abstract}
Incorporated groupware can gather people of various skills around the globe to share their knowledge while working on a project. Internet, intranet, and other groupware technologies, such as Lotus-Notes, video conferencing and e-mail can be used to distribute and share individual experience and innovation throughout the organization. Therefore, Organizations especially those adapting to rapidly changing environments, face the challenge of being able to use these technologies, in order to gain knowledge sharing effectively within highly constrained timeframes. There are many environmental factors have effect on using these technologies. This study came to explore the effect of organizational culture on using electronic collaborative media. This study investigated a sample formed of (180) individuals operating in a number of hospitals within the Jordanian health sector; using the electronic collaborative system, to perform its different duties. In order to achieve this purpose the study proposed the following hypotheses: organizational culture is positively influences on using electronic collaborative media.
\end{abstract}

Keywords: Electronic collaborative media, knowledge sharing, organization culture, communication tools.

\section{INTRODUCTION}

Knowledge revolution, information technology and communication led to a change in the strategic concepts and the tools used by the organizations that seek for learning, competitive and obtaining high market shares. These basic and qualitative changes imposed new concepts pushed organizations to exert efforts and make big investments in order to cope with the internal and external environmental changes. ke and Wei[1]; Al-Alawi[2]. Hawryszkiewycz[3] argued that Knowledge development and sharing is becoming increasingly important in many organizations. The quick development and changes in information technology provided many tools can be used by the organizations or their employees in order to obtain knowledge. Tools such as Electronic mail, groupware, and the other collaboration systems are considered among the most important tools, through which the organizations were able to reach advanced levels of knowledge. Bhatt et al [4] argued that Information system tools, including electronic discussion groups, knowledge portals, and chat-rooms can open up many windows for discussion and exchange of ideas and personal experience. For example, Lotus Note applications, internet discussion groups, and chat-room experiences can support geographically distributed people in brain storming and new idea discussion processes.

\section{THEORETICAL BACKGROUND \\ 2.1 Electronic Collaborative Media}

The new development of information technology and communications allowed the use of computers in all the fields of social-economic life, including the education field especially higher education Paraschiv et al [5]. Knowledge sharing through the internet between the firm, its customers, and its suppliers is important to promote the process of knowledge management Egan and kim[6]. Graveline[7] argued that people have begun to use communication technologies to collaborate at a distance, to enhance the way operation done. These technologies used to decrease costs and increase productivity and give employees greater flexibility in their work life by enhancing communications between organizations. There are a large number of tools and methodologies to facilitate e-collaboration inside and outside organizations, such as groupware tools which refer to software products that support collaboration over networks among groups of people or employees who share a common task or goal. More of these tools are available on the internet or an intranet to enhance collaboration process of people in the same place or over the world. So if any organization wants to adopt these technologies they have to prepare the infrastructure needed from hardware to groupware, such as Internet, intranet, extranet, and wireless technology. These tools provide collaboration in two types: synchronous and asynchronous mode. Turban [8]; O'Briens [9] argued that information technology playing important role in changing the way people work together. Especially internet, intranet and extranet technologies; because these technology help to achieve communication, coordination and collaboration functions. Also he categorized electronic collaboration media into three groups: Electronic Communication Tools: e-mail, voice mail, faxing, web publishing, and internet phone. Electronic Conferencing Tools: data conferencing, voice conferencing, video conferencing, discussion forums, chat systems, electronic meeting system. $\square$ Collaborative Work Management Tools: calendaring and scheduling, task and project management, workflow systems, document sharing. Bajwa[10] named these tools as CIT (collaborative information technology) and classified them to seven clusters; in addition he lists examples for each cluster like that:

-Email like Microsoft Outlook, Hotmail.

-Teleconferencing (two-way audio) like

( NetMeeting, CU-SeeMe).

-Videoconferencing (two-way audio and video)

like (NetMeeting, CU-SeeMe).

-Data conferencing (whiteboards, application

sharing, data presentations)

-Web-based Collaborative Tools (Intranets,

Listservs, Newsgroups, chat, message boards).

-Electronic Meeting Systems

Like (GroupSystems, MeetingWorks, TeamFocus). 
The following figure show how these tools classified depending on two diminutions time/place:

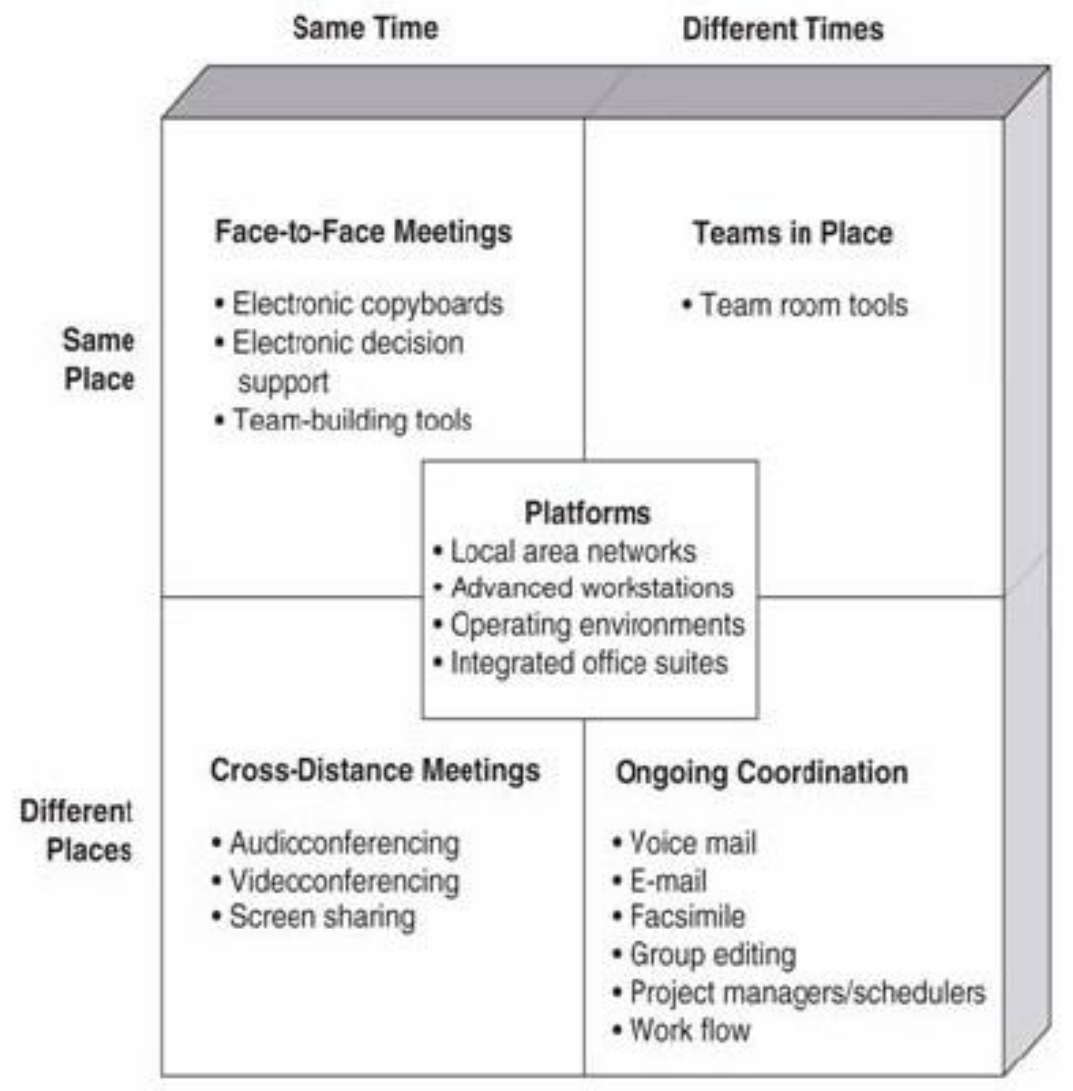

Fig (1): Electronic Collaborative Media Classification. Source: Source: Barbra [36], Information Systems Management in Practice, Sixth Edition, Prentice Hall

\subsubsection{The Benefits from Using Electronic Collaborative Media}

There are many benefits to adopt and use of electronic collaborative media , such as Supply Chain Management, Knowledge Management, Knowledge Sharing, Information Sharing between retailer and supplier, reduction of design cycle time, reduction of product development time, collaborative commerce, brainstorming, decision support system Turban[8]. Also Hofte[12] emphasized these tools will play big roles in collaborative learning generating more of motivations, responsibility, productivity, communication skills, and skills for working as virtual teams. MATUŠU et al [13] argued that " The key idea of technology-enhanced learning is to support learning activities via information technology".

\subsubsection{Related Issues of Electronic Collaborative Media}

Using electronic collaborative media become wide spread among organizations, so organization faced many problems related with this developments, because many communication technology available for distributed team to use, as example on these problem is how the organization could choose the best suited option for their activities and tasks among these available media. One of the most theories related to these issues is media richness theory proposed by Daft and Lengel [14]. Theses theory defines several characteristics of media such as:
-Feedback Capability: refers to synchronous and asynchronous media, e-mail is an example on asynchronous media, and instant chat is an example on synchronous media.

- Availability of multiple cues: some of media has various numbers of communication channels like conferencing software, and single channel like e-mail.

- Language variety: the capability to use different types of language.

- Personal focus: refers to Socio-emotional content a message contains.

Also Daft and lengel [14] define two types of communication situations ambiguous and uncertain situations. From another perspective using these tools are affected by many factors. Kim and Lee [20] argued that there are many determinate factors of EDI implementation such as Organizational structural characteristics (decentralization, formalization), Technical Characteristics (technical compatibility), Managerial characteristics (education and training, top management support). Chen and Sen[15] suggested that adopting Web services applications depends on the company's current IT infrastructure status (intranet, extranet, and Internet). Jarvenpaa and Staples [16] argued that organizational culture has an important effect on using electronic mail, World Wide Web, list serves, and other collaborative systems. 


\subsection{Organizational Culture}

Many of the definitions were proposed from many researchers. Although there is no widespread agreement on exactly what organizational culture is, because every one defines it by his perspective. One of the most common definitions of organizational culture includes shared values, beliefs, attitude, and norms (Schein 1992[17]; Dension and Mishra [18]; Jones [19]). Jones [19] defines organizational culture as the set of shared norms, assumption, and values that determines how employees and mangers in organization should behave, in addition it identifies what the organization considers important or not. Denson and Mishra [18] look to organizational culture as member's beliefs, values, and assumptions in addition to, the practices and behaviors that exemplify and reinforce them. Lemken and Kahler [20] look to organizational culture as organizational aspect that forms the environment in which information and experiences can flow. We define organizational culture as a set of values, thoughts, beliefs and laws that prevail inside organization which controlling member's behaviors. This culture changes according to information and knowledge sharing between organization members, through electronic collaboration media which facilitates these processes. This can occur when the organization possesses a motivated culture to use electronic collaboration system in knowledge sharing.

\subsubsection{Importance of Organizational Culture}

Despite continuing initiatives, new business models, and technology developments, organizational culture still play a very important role in achieving success in an organization process. It has impact in many aspects in organizations such as, initiatives, employees effectiveness, facilitating the communication between employees and business partners, knowledge transfer, knowledge management, knowledge sharing, employees satisfactions, use of information technology accounting forum, use of e-collaborative media, technology adoption and use, and many others aspects. In conclusion, organization culture will determine the competitive position of organizations. The following points are collected from some literatures reviews that mention the impact of the organizational culture:

1- Organizational culture policy has a big role to generate more of opportunities to create knowledge.

2- Organization culture effects on organization learning capability. Bhatt [21]

3- Using electronic collaborative media to knowledge sharing will not be effective if there is no organizational culture conduces knowledge sharing. Kock[22]

4- Organizational culture openness and respect of the personal privacy is very important to lead to the ability of the communicators to trust their medium.

5- Organizational culture and personal attributes of the employees are important factors that effect on the success or failure of the email system.

6- Organizational culture has a big effect on employees' decision to share their knowledge or not. Chaudhry[23]

7- Organizational culture has a powerful effect on the performance and efficiency.

Masood et al [24].

8- Organizational culture effects on groupware applications, which are designed to Support people engaged in cooperative work (CSCW). Hofte et al [25].
9- It is important to interact between organizational culture, technique and Technologies within Organization to sustain their competitive advantages. Bhatt [26]

In addition to the previous benefits, I suggest that organization culture will effect on using of e-mail and intranet. In recent years organizations use the intranet technology to execute their operation widely. So it must understand existing organizational culture before implementation of this new technology.

\subsubsection{Organizational Culture Measures and Models}

The researchers who have conducted studies on culture attempts to collect many of elements and dimensions of culture to build measurable cultural models. There are numerous culture instrument were developed but few that meet the test reliability and clear evidence of validity. One of these models is organizational culture inventory (OCI) by (Cooke \& Lafferty 1987). This instrument provides three categories of culture: constructive norms, passive-defensive norms, aggressivedefensive norms Jashapar[27]. Denison and Mirsha[18] have conducted several studies to explore the impact of organizational culture on organizations performance. Denison and his colleague's are proposed Denison organizational culture Model. This model has four organizational culture traits that have an impact on performance in organizations. These traits are arranged as follow: Involvement (empowerment, team orientation, and capability development), Consistency (core value, agreement, and coordination), and Adaptability (creation change, customer focus, organizational learning) and Mission (vision, strategic decision, goals and objectives)

Hofsted's cultural dimensions are the most cited references about cultural within IS literature which is suggested by Hofsted's 1980 including four value dimensions that differentiate national character: $\square \square$ power distance, Individualism versus collectivism, Masculinity versus femininity, Uncertainty avoidance. Then in 1990 Hofstede et al add this tow organizational culture factor (need for achievement, democraticness). Goffee and Jones [28] defined and developed measures for two dimensions of corporate culture that relate to producing and maintaining the well-being and the integrity of other partners; sociability and solidarity. Sociability is a measure of sincere friendliness among members of a community, in addition to enhance teamwork, encourage information and knowledge sharing, and create new idea and innovations. Solidarity is a measure of a community's ability to pursue shared objectives quickly and effectively, in addition to create sharing focus and trust. Some of researchers argue that, quantitative methods is enough to measure organizational culture such as Saryrae [29], but another researchers emphasized that quantitative methods is not enough to measure organizational culture such as Denison and Mirsha[18]). We agreement with the last suggestion, so will use qualitative and quantitative methods to measure organizational culture. After deeply scanning for organizational culture study we choose the following dimensions as shown in table bellow. 
Table (1) organizational culture constructs.

\begin{tabular}{|c|c|c|}
\hline Dimension & Definition & Source \\
\hline Shared Views & $\begin{array}{l}\text { Clear views aiming to achieve shared goals and polices } \\
\text { within organization. }\end{array}$ & $\begin{array}{l}\text { Dension,1990,Soley and } \\
\text { Pandya,2007; Kim and Lee,2005. }\end{array}$ \\
\hline Involvement & $\begin{array}{l}\text { Sense of ownership and responsibility among a firm's } \\
\text { members. }\end{array}$ & $\begin{array}{l}\text { Denison and Jones, 1996; Staples } \\
\text { and Javenpaa,2000 }\end{array}$ \\
\hline Trust & Confidence : a trustful relationship. & $\begin{array}{l}\text { Kim and Lee,2005,Price, 2003; } \\
\text { Lemken and et al; } 2003\end{array}$ \\
\hline Sociability & $\begin{array}{l}\text { It is a measure of science friendliness among members of a } \\
\text { community. }\end{array}$ & $\begin{array}{l}\text { Goffee and Jones, 1996; Staples } \\
\text { and Jarvenpaa, 2000. }\end{array}$ \\
\hline $\begin{array}{ll}\text { Need } & \text { for } \\
\text { Achievement } & \end{array}$ & $\begin{array}{l}\text { Focuses on the importance of advancement and prestige; } \\
\text { referring to an individual's desire for significant } \\
\text { accomplishment, mastering of skills, control, or high } \\
\text { standards. }\end{array}$ & $\begin{array}{l}\text { Hofsted et al, 1990; Hansemark, } \\
2003 \text {. }\end{array}$ \\
\hline
\end{tabular}

\section{RESEARCH MODEL}

This research aims to investigate the impact of organizational culture on using electronic collaborative media. Because there is scarcity of the studies related to this study in our area, we start with an exploratory phase to gain an in depth understanding of phenomenon construct and formulate the research hypotheses. In this research, the exploratory phase starts with semi-structured interviews aiming to develop an understanding of the following issues: The common electronic collaborative media used to exchange knowledge inside and outside hospitals. The important contextual organizational factors concerned with using electronic collaborative media in hospitals. To what extent has knowledge sharing been realized and actually applied in hospitals.

According to Smith [43] he argued that the use of semistructured interviews will help researcher obtain more information, about participant's beliefs, or perception of particular phenomenon. Depending on semi-structured interviews and literature we posed the following model:

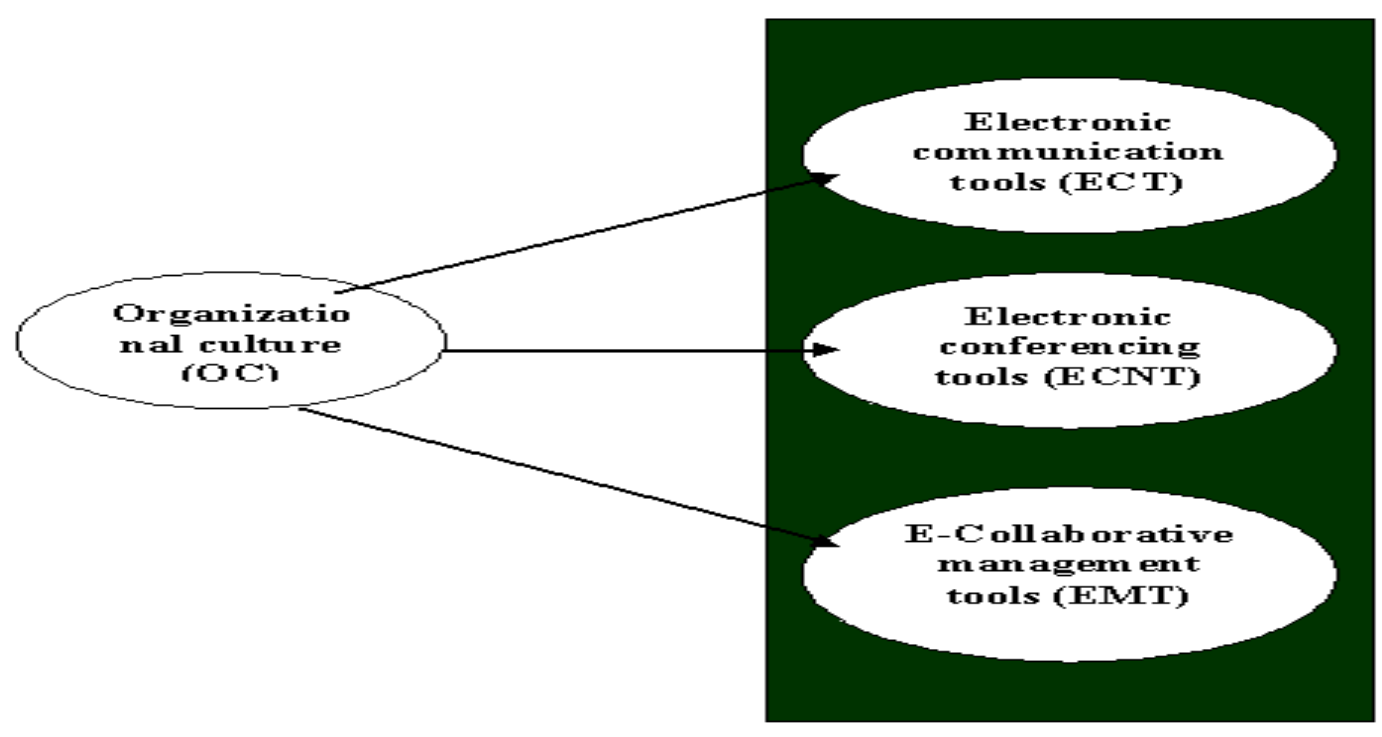

Fig (2): The suggested model of the study

To test the suggested model we posed the following hypothesize:

H0: Organizational culture has not a positive effect on Using Electronic Collaborative Media 


\section{METHODS}

We have chosen hospitals belonging to the Health care sector in Amman city to conduct the study for the following reasons:

1- The importance of the role played by researched hospitals in Jordan society.

2- The researched sector is the best example where the relation between study variables and research subject becomes clear.

3- Sincerity of researched hospitals to use modern and innovated methods in performing their works.

The study sample included department directories and heads of administrative and vocational section of study community's hospitals, as well as those having information a bout their hospitals duties, availability of electronic collaborative tools and application aspect to mange knowledge sharing. Therefore there was a total of (210) persons, constituting the study sample forming $(43 \%)$ of the whole community which were 470 persons. There were (190) questionnaires which have been retrieved of which have been discarded because of being invalid for statistical analysis, so the real number of study sample is (180) persons constituting (37\%) percent of whole community and it is acceptable in such type of this studies.

\section{SURVEY MEASURES AND ITEMS}

The self-administered questionnaire was designed to elicit demographic data, information about organizational culture and information on employee perceptions of using electronic collaborative media. Some of items used in this survey were adapted from previous studies. Responses were recorded along a five-point Likert scale ranging from $1=$ strongly disagree to $5=$ strongly agree. Cronbach alpha reliability estimates for all variables. The factor loadings support the use of these items as indicators of the constructs they were designed to measure.

Using electronic collaborative media dimension were dived into three construct as shown in the fig (1.1) adapted from O’Briens[9]; Hofte[25].

Electronic communication tools construct was assessed with a five-item scale which was a) 'The hospital use application software which allows interested employees to contribute their ideas relating to certain subject"; b) "The employees within the hospital rely on fax machine to send or receive documents"; c) " The employee rely on voice male as a method of communication to exchange information within the hospital"; d) " The employee rely on electronic email to exchange information inside or outside the hospital"; e) "The hospital uses application software which enables publishing of information on web site." The Cronbach alpha reliability of the five items was measured as $0.79, \mathrm{KMO}=0.82$, factor loading $=0.74$, mean $=3.5$, standard deviation $=0.90$.

Electronic conferencing tools construct was assessed with a sixitem scale which was a) "Video conferencing is used to exchange information and special experiences related to the employee job within the hospital"; b) " The hospital provide special application software which help employees to perform shared tasks"; c) "The employee rely on the chatting software on the internet for real time exchange of information and special experience related to their job within the hospital"; d) " The hospital provide special electronic meeting technology to conduct meeting inside or outside the hospital"; e) "Electronic Bulletin Board is used to exchange information within the hospital"; f) "The employee rely on the forum available through the internet to exchange information and special experience related to their job within the hospital." The Cronbach alpha reliability of the five items was measured as $0.81, \mathrm{KMO}=0.824$, factor loading $=0.72$, mean $=3.4$, standard deviation $=0.99$.

E-Collaborative management tools construct was assessed with a six-item scale which was a) "The hospital provides an extranet which enables exchange of information with other business partners"; b) " Workflow system is used within the hospital to transfer information related to task execution mechanism"; c) "Specialized computer systems are used to manage different functional activates"; d) " The hospital poses application software which include many methods to share knowledge"; e) "The hospital poses an intranet that links all of the employees within the hospital"; f) "The employees in the hospital rely on electronic memos to coordinate appointment and task scheduling related to individual." The Cronbach alpha reliability of the five items was measured as $0.75, \mathrm{KMO}=0.82$, factor loading $=0$ .69 , mean $=3.3$, standard deviation $=0.98$.

Organizational culture dimension were dived into two construct as shown in the fig(2) adapted from Soley and Pandya[30]; Kim and Lee[31]; Denison and Mishra[18]; Goffee and Jones[28]; Jarvenpaa, and Staples [32]; Price[33]; Lemken et al[20].

Organizational culture construct was assessed with a seven-item scale which was a) " The hospital management hold a clear and shared vision of what it will be like in the future"; b) "The hospital management attempts to place strategic goals which are realistic and possible

to achieve in the future"; c) "Information is widely shared in away that any one can access this information when needed"; d) "The hospital rely on teamwork to achieve shared goals in a collaborative manner"; e) "The employees have social interaction inside and outside the hospital"; f) "The hospital management concentrate it is effort to achieve a distinctive position among similar hospital; g)" Trust prevails among individuals employee within the hospital".

The factor analysis indicated the existence of two factor solution of organizational culture. The first factor contains 4 item (Question 3, 2, 1, and 6) related to management culture and the second factor related to social culture (Question 7, 4 and 5), with total variance explain to factor one was 31.50 for the second factor was 21.54., $\mathrm{KMO}=0.84 \mathrm{The}$ Cronbach alpha reliability of the factor one was measured as 0.70 , The Cronbach alpha reliability of the second factor was measured as 0.61 , mean $=$ 3.31 , standard deviation $=0.88$.

According to the factor analysis that have been done, the researcher have adjusted the suggested research model in order to meet the changes that emerged from the analysis, by dividing the organizational culture dimension into two factors as shown in the fig(3): 


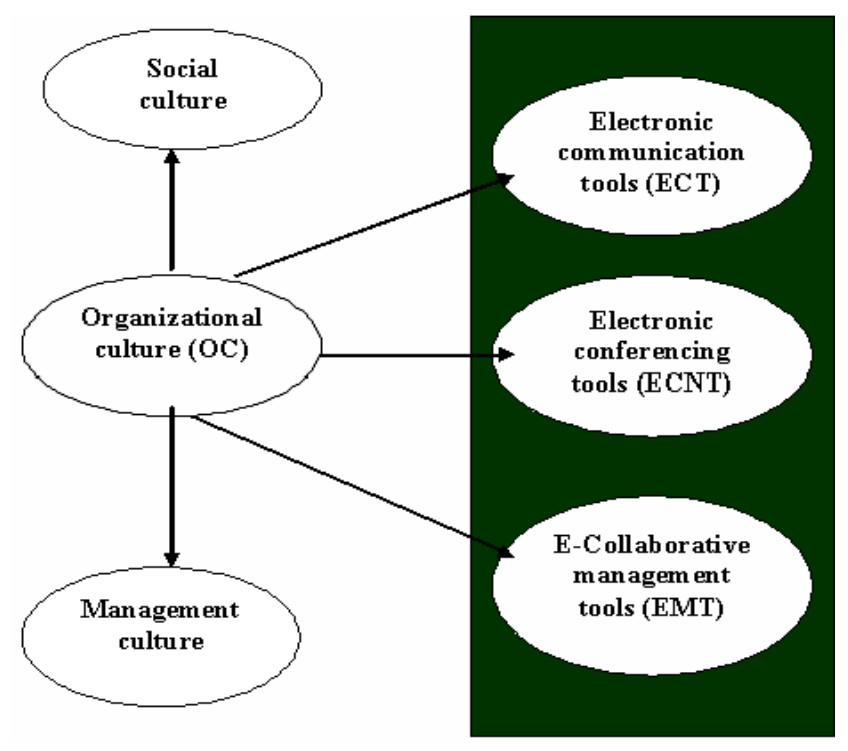

H0: Organizational culture has not a positive effect on Using Electronic Collaborative Media.

H1: Organizational culture has a positive effect on Using Electronic Collaborative Media.

Fig (3): The adjusted model of the study

\section{RESEARCH FINDINGS AND CONCLUSIONS}

Hypothesis testing results:

Table (2): Multiple Regression Test

\begin{tabular}{|l|c|c|c|c|c|c|}
\hline \multicolumn{1}{|c|}{ Variable } & $\mathbf{R}$ & $\mathbf{R}$ Square & $\begin{array}{c}\text { Adjusted } \\
\mathbf{R}\end{array}$ & Durban W & F & Sig \\
\hline $\begin{array}{l}\text { Using Electronic } \\
\begin{array}{l}\text { Collaborative } \\
\text { Media }\end{array}\end{array}$ & .761 & .522 & .519 & 1.627 & 187.110 & .000 \\
\hline
\end{tabular}

Predictors (constant): Social culture (OSC), Management culture

$(\mathrm{OCM})$

Table (3): Coefficient Table

\begin{tabular}{|c|c|c|c|c|c|c|c|}
\hline \multicolumn{4}{|c|}{$\begin{array}{cc}\text { Unstandardized } & \text { Standardized } \\
\text { Coefficients } & \text { Coefficients }\end{array}$} & $\mathrm{T}$ & Sig & \multicolumn{2}{|c|}{ Collinearity Statistics } \\
\hline Constant & $\begin{array}{l}B \\
.543\end{array}$ & $\begin{array}{l}\text { Std Error } \\
.070\end{array}$ & Beta & 8.032 & .000 & Tolerance & VIF \\
\hline OSC & .367 & .025 & .401 & 15.323 & .000 & .644 & 1.33 \\
\hline $\mathrm{OMC}$ & .192 & .021 & .181 & 8.549 & .000 & 598 & 1.27 \\
\hline
\end{tabular}

According to table (2) the multiple correlation coefficient $\mathrm{R}=$ .716 indicated that there is a strong correlation between Using Electronic Collaborative Media and those predicted by the regression model, $\mathrm{R}$ square $=.52$ which means that organizational culture (Social culture, Management culture) explained $52 \%$ of variance in Using Electronic Collaborative Media. The adjusted R2 is an attempt at improved estimation of $\mathrm{R}$ square in the population. Use of this adjusted measure leads to a revised estimate .519 of the variability in Using Electronic Collaborative Media can be explained by the tow explanatory variables.

F value equal 187.110 with significant equal .000 , therefore we reject the null hypothesis and accept the alternative which indicate that there is an effect of organizational culture on Using of electronic collaborative Media. Table (2) also show that the Durbun Waston test equal 1.627 which means that there is no autocorrelation between independent variables.

Table (3) depicts which of independent variable has a significant effect on using electronic collaborative media. It shows that there is positive relation organizational social culture (OSC) and using electronic collaborative media where Beta equal .401(T equal 15.323, Sig equal .000). There is positive relation between organizational management cultures (OMC) and using electronic collaborative media where Beta equal .181(T equal 8.549, Sig equal .000). Collinearity statistics shows that the VIF values are less than 10 and tolerance values above 0.1 so there is no collinearity between independent variable which indicates the power of study model. 


\section{CONCLUSION AND FURTHER RESEARCHER RECOMMENDATION}

This study proposed that using of electronic collaborative media has affected by organizational culture. The results of the proposed examination indicated the presence of significance effect of organizational culture in using electronic collaborative media the hospital under study, whereas the three dimensions of this variable (ECT, ECNT, and EMT) have a significance affected by organizational culture.

These results coincide with the meetings that were held by the researcher, and with the other previous studies such as Hofte, 1996; Chaudhry, 2005; hvovinen, 2005. Hofte(1996) argues that Organizational culture effects on groupware applications, which are designed to support people engaged in cooperative work Chaudhry( 2005) finding that Organizational culture has a big effect on employees decision to share their knowledge or not. Also hvovinen(2005) argued that Organizational culture and personal attributes of the employees are important factors that effect on the success or failure of the email system.

This consistency between the results and literature review confirms that organizational culture plays an important role in achieving suitable electronic collaborative media system; therefore organizations must take into consideration their organizational culture and prepare suitable environment for these tools before applying any new electronic collaborative media system in order to achieve a higher success.

\subsection{Recommendation for Electronic collaborative media}

1-To work on reduce the gab resulted of the variance by using electronic collaborative tools that may be reduced the advantages for the hospitals to use these tools at a comprehensive and integrated aspect.

2-To increase the use of voice mail as an electronic tool that affects to achieve the effective performance for the hospitals.

3 -There is a necessity to follow-up the quick developments in electronic collaborative tools to provide and to use the recent tools to facilitate knowledge sharing.

4-There is a necessity to develop and develop work flow systems that explained work performance stages and procedures besides the special level to achieve work and ideal performance time.

\subsection{Recommendations for Organizational culture}

1- To work on create and promote the confidence among the workers at researched hospitals by increasing social interaction among them.

2 -There is a need to increase the reliance on teamwork to perform the tasks and missions of hospital.

\section{REFERENCES}

[1] Ke, W., and Wei, K.K., Critical factors affecting the firm to share knowledge with trading partners: a comparative exploratory case study, Proceedings of the 7th international conference on Electronic commerce, Vol.113, 2005.

[2] Al-Alawi, A.I., Al-Marzooqi, N.Y., and Mohammed, Y.F.,Organizational culture and knowledge sharing: critical success factors, ournal of Knowledge Management, VOL. 11, NO. 2, 2007, pp.22-42.

[3] Hawryszkiewycz, 2000, Evolving Knowledge Intensive Community Networks, In Proceedings of Ausweb.
[4] Bhatt, G., Jatinder, N.D, and Kitchens, F.G., An Exploratory Study of Groupware Use in the Knowledge Management process, The Journal of Enterprise Information Management,Vol. 18 No. 1, 2005, pp. 28-46.

[5] Paraschiv, N., Popovici, S., Stocia, D.,2008, Online laboratory based on web technology, 4th Wseas/Iasme (EDUTE'08) Corfu, Greece.

[6] Egan, M., and Kim ,J., Building A better Knowledge Sharing Tool with the YourNet Intranet, Knowledge Management Review, Vol.3 , No.3, 2000.

[7] Graveline, A. Geisler, C. Danchak, M., Teaming Together Apart: Emergent Patterns of Media Use Incollaboration at a Distance, Proceedings of 2000 Joint IEEE International and 18th Annual Conference on Computer Documentation (IPCC/SIGDOC 2000), pp.381-393: ACM.

[8] Turban, (2004) E., Electronic Commerce A Management Perspective, Third Ed, Prentice Hall.

[9] O'Brien James,(2004) Management Information Systems: Managing Information Technology in the Business Enterprise, 6th ed. McGraw- Hill, pp. 523-538.

[10] Bajwa,(2004) S., Lewis, F.L., and, Pervan, G., An Empirical Assessment of the Adoption and Use of Collaboration Information Technology in the US, The IFIP TC8/WG8.3 International Conference, pp. $60-69$.

[11] Barbra, C.,(2003) Information Systems Management In Practice, Sixth Edition, Prentice Hall.

[12] Hofte, T.H.Lugt, H., Maurice A., Houtsma,.M. , A(1996) Comprehensive Model of Groupware Functionality,APTEC conference of Euromedia'96, London, UK, December, 1996.

[13] MATUŠŮ, R., VOJTĚŠEK, J., DULÍK, T., (2008) Technology-Enhanced Learning Tools in European Higher Education, Proceedings of the $8^{\text {th }}$ WSEAS International Conference on MULTIMEDIA, INTERNET \& VIDEO TECHNOLOGIES.

[14] Daft, R.L., and Lengel, R.H.,(1984) Information Richness: A new Approach to Managerial Behavior and Organizational Design, Research in organizational behavior, Vol. 6 .

[15] Chen, A.K., and Sen, S.(2006), Strategies for Effective Web Services Adoption for Dynamic E-businesses, Decision Support Systems, Vol. 42, pp: 789-809.

[16] Jarvenpaa, L.S, Staples, S.D., (2000) The Use of Collaborative ElectronicMedia for Information Sharing: An Exploratory Study of Determinants, Journal of Strategic Information system, Vol.9, pp: 129-154.

[17] Schein, E. H. (1992). Organizational culture and leadership, (2nd Ed.). San Francisco: Jossey-Bass.

[18] Denison, D. R., and Mishra, A. K. (1995), Toward a Theory of Organizational Culture and Effectiveness, Organization Science Vol.6 No.2, pp: 204-223.

[19] Jones,J.R.(2000), Organizational Theory, Decision and Change : Text Cases, Third Ed, Prentice Hall:54.

[20] Lemken, B., Kahler,H., and Rittenbruch, M.(2000), Sustained Knowledge Management by Organizational Culture, Proceedings of the 33rd Hawaii International Conference on System Sciences:IEEE. 
[21] Bhatt, D.G. (2000), Information Dynamics, Learning and Knowledge Creation in Organizations .The Learning Organization, Vol. 07 No.2, pp: 89-98.

[22] Kock, N.(2000), Sharing Interdepartmental Knowledge using Collaboration Technologies: Action Research Study, Journal of Information Technology Impact, Vol. 2, No. 1.

[23] Chaudhry, S.A.(2005), Knowledge sharing practices in Asian institutions: a multicultural perspective from Singapore, Knowledge Management, World Library and Information Science: 71th IFLA General Conference and Council.

[24] Masood, A.A., Dani, S.S., Burns, D.N., and Backhouse, J.C. (2006), Transformational Leadership and Organizational Culture: The Situational Strength Perspective, In Proceedings of the Institution of Mechanical Engineers, Part B: Journal of Engineering Manufacture, Vol.220, No. 6.

[25] Hofte, T.H. Lugt, H., Maurice A., Houtsma, .M. (1996) , A Comprehensive Model of Groupware Functionality,APTEC conference of Euromedia'96, London, UK, December 1921.

[26] Bhatt, D.G. (2001), Knowledge Management in Organizations: Examining the Interaction between Technologies, Techniques, and people, Journal of Knowledge Management Vol.5, No. 1, pp: 68-75.
[27] Jashapar, A.(2003), Knowledge Management and Integrated Approach, Prentice Hall.

[28] Goffee, R., and Jones, G.(1996), What Holds the Modern Company Together? Harvard Business Review, pp. 133148

[29] Saryrih, A.(2003), Relationship between systematic culture and administrative creation in Potash Industrial Public Companies in Jordan, Humanities and Social Science Series, Vol 8, pp 187:237.

[30] Soley, M., and Pandya, V.K.(2003), Culture as an Issue in Knowledge Sharing: A Means of Competitive Advantage, Electronic Journal on Knowledge Management, Vol. 1 No. 2.

[31] Kim, G.B., Lee, S.(2007), Factors Afecting the Implementation of Electronic data Interchange in Korea, Computers in Human Behavior, Vol. 13.

[32] Jarvenpaa, S. L. \& Staples, D. S. 2000. The use of collaborative electronic media for information sharing: an exploratory study of determinants, Journal of Strategic Information Systems, Vol. 9: 129-154.

[33] Price, C.A. (2003), A Culture Assessment of XYZ Manufacturing Company, Master Thesis, University of Wisconsin-Stout. 